\title{
Women's Body Image Distress Associated with Cervical Cancer
}

Soad Ramadan ${ }^{1}$, Hanan Elzeblawy Hassan ${ }^{2}$, Hagar Masaud ${ }^{3}$ and Ragaa Mohammed ${ }^{4}$

${ }^{1}$ Professor of Obstetrics and Women Health Nursing, Faculty of Nursing, Benha University, Egypt

${ }^{2}$ Associate professor Maternal and Newborn Health Nursing, Faculty of Nursing, Beni-Suef University, Egypt

${ }^{3}$ Assistant lecturer of Maternal and Newborn Health Nursing, Faculty of Nursing, Beni-Suef University, Egypt

${ }^{4}$ Professor of Maternity \& Neonatal Nursing, Faculty of Nursing, Cairo University, Egypt

*Corresponding Author: Hanan Elzeblawy Hassan, Associate professor Maternal and Newborn Health Nursing, Faculty of Nursing, Beni-Suef University, Egypt.

Received date: February 18, 2021 ; Accepted date: March 13, 2020; Published date: March 20,2021

Citation: Hanan E Hassan., (2021) Women's Body Image Distress Associated with Cervical Cancer J. Obstetrics Gynecology and Reproductive Sciences 5(3); DOI: 10.31579/2578-8965/062

Copyright: () 2021, Hanan Elzeblawy Hassan, This is an open access article distributed under the Creative Commons Attribution License, which permits unrestricted use, distribution, and reproduction in any medium, provided the original work is properly cited.

\section{Abstract}

Background: Cervical cancer diagnosis and treatment can bring changes related to a woman's body image; which in turn can have a devastating on intimate relationships.

Aim: The present study aimed to assess women's body image distress associated with cervical cancer.

Methods; Design: A descriptive design was conducted. Setting: out-patient clinic in the oncology unit at Beni-Suef University hospital. Subjects: A purposive sample of 70 women. Tools: Data was collected through a structured interviewing questionnaire sheet, and body image scale.

Results: The results of the study indicate that the majority (90\%) of the studied women had body image distress. There is a statistically significant relationship between age and marriage age of women and their total body image scores.

Conclusion: There is a statistical association between body image statuses amongst those women who were undergoing cervical cancer treatment concerning their socio-demographic characteristics.

Recommendations: Implement an educational program to improve the self-body image for women with cervical cancer.

Keywords: Cervical cancer, Body image

\section{Introduction}

Cervical cancer affects all aspects of a patient's life, self-concept, and body image, as well [1-6]. Cervical cancer is the $4^{\text {th }}$ most frequent cancer in women; it represents $6.6 \%$ of all female cancers. Approximately $90 \%$ of deaths from cervical cancer occurred in low and middle-income countries [7].

Cervical cancer occurs when the cells of the cervix grow abnormally and invade other tissues and organs of the body [8-10]. Cervical cancer is a type of cancer that occurs in the cells of the cervix. Various strains of the human papillomavirus (HPV), sexually transmitted infections, play a vital role in causing most cervical cancer [11-14].

Pitcher et al., stated that 'Body image' relates to how one mentally perceives and subjectively experiences his or her body. [15] The term "body image" as defined by National Cancer Institute reflects how to feel the body is aesthetically and how attractive one perceives one's body. Throughout history, humans have regarded the beauty of the human body is important [16-18]. Cervical cancer diagnosis and treatment can bring changes related to a woman's body image which in turn can have a devastating on intimate relationships [19-20].
Body image and intimacy after cancer may be different, but different does not mean better or worse. To adapt to these changes, women may need to develop more openness and confidence, in and out of the bedroom [21].

Nurses play a vital role in health care provision. Nurses educate patients regarding medications, diseases, treatment, lifestyle changes, and discharge from the hospital. This education can be informal, part of daily care, or given in more formal teaching [22-28]. Nurse is a caregiver for patients and helps to manage physical needs, prevent illness, and treat health conditions. To do this, nurses need to observe and monitor the patient, recording any relevant information to aid in treatment decisionmaking. Throughout the treatment process, the nurse follows the progress of the patient and acts accordingly with the patient's best interests in mind. The care provided by a nurse extends beyond the administration of medications and other therapies; nurses are responsible for the holistic care of patients [13]. The nurse also guides the cervical cancer survivor to regain self-confidence and adapt to physical and psychological changes to optimize survivor autonomy [1]. Survivors of cervical cancers and their spouses need help from health care personnel, especially nurses, to overcome their body image distress problems [29-34]. 


\section{Aim of the study}

The current study aims to assess women's body image distress associated with cervical cancer

\section{Research Questions}

Is cervical cancer could affect a woman's body image?

\section{Subjects and methods}

\subsection{Research Design}

A descriptive design was used for the current study.

\subsection{Setting}

The oncology unit at Beni-Suef university hospital.

\subsection{Subjects:}

The sample size was 70 women; were diagnosed and undergoing treatment of cervical cancer

\subsection{Tools of Data Collection}

To attain the aim of this study, two tools were used for data collection;

4.4.1. Tool I: Structured interviewing questionnaire sheet was developed by the researcher in the Arabic language based on a review of recent literature. It was consisting of two parts:

1. Part 1: Socio-demographic characteristics of women as age, level of education, occupation, and residence.

2. Part 2: Obstetric and gynecological history: age of menarche, the regularity or absence of menstrual period, and parity number.

\subsubsection{Tool II: Body Image Scale.}

It is a self-report measure of the woman's body image. This 10-item scale was constructed in collaboration with the European Organization for Research and Treatment of Cancer (EORTC) designed by Hopwood et al., 2001. [35] The scale showed high reliability (Cronbach's alpha 0.93) and good clinical validity. Scores on the body image range from 9 to 36 . The good level was 9-17, a considerable level was 18-26 and the bad level was 27-36. Lower scores indicate a greater level of body image.

\subsection{Validity and Reliability:}

Data collection tools were submitted to three experts in the field of maternity/obstetric nursing to test content validity.

\subsection{Administrative \& Ethical Considerations:}

Approval was got from the Beni-Suef University hospital director. All engaged women were informed that participation is voluntary and have the right of accepting or refusing participation in the study.

\subsection{Pilot study:}

A pilot study was conducted on $10 \%$ ( 7 women). The pilot sample was excluded from the main study sample.

\subsection{Statistical analysis}

The collected data was revised, coded, tabulated, and introduced to a PC using a statistical package for social sciences (IBM SPSS 25.0). Data was presented as:

- Mean and Standard deviation (SD) and range.

- Frequency and percentage.

- Chi Square $\left(\mathrm{X}^{2}\right)$

- Colum and Pie chart for graphic presentation

\section{Results}

Figure (1) reveals that approximately slightly less than one-quarter $(21.4 \%)$ of the study sample their age ranged from 30 to 40 years old and more than half $(51.4 \%)$ their age more than 50 years old with a mean age of $49.4 \pm 9.38$. Regarding the educational level of women, slightly less than one-half $(48.6 \%)$ had a secondary education. Regarding the occupation, more than one-half $(64.3 \%)$ of women were housewives. Regarding residence, more than one-half $(52.8 \%)$ of women was from urban areas and the mean age of marriage for women was 19.1 \pm 4.23 .

Table (1) illustrates that more than three-quarters (78.6\%) of the studied women had menarche by the age of $12: 15$ years old while only $2.8 \%$ of women had menarche after the age of 15 years old. Regarding menstrual regularity, slightly less than one-half $(41.4 \%)$ of studied women had amenorrhea and one-quarter $(25.7 \%)$ had regular menstruation. Regarding number of parity, more than half $(62.8 \%)$ of women had more than three deliveries and only $(1.4 \%)$ were nulliparous.

Figure (2) indicates that more than three-quarters (90\%) of the studied women had body image distress.

Table (2) illustrates that there was a statistically significant relationship between age and marriage age of women and their total body image scores, while there was no statistically significant relationship between educational level and residence of women and their total body image scores. 


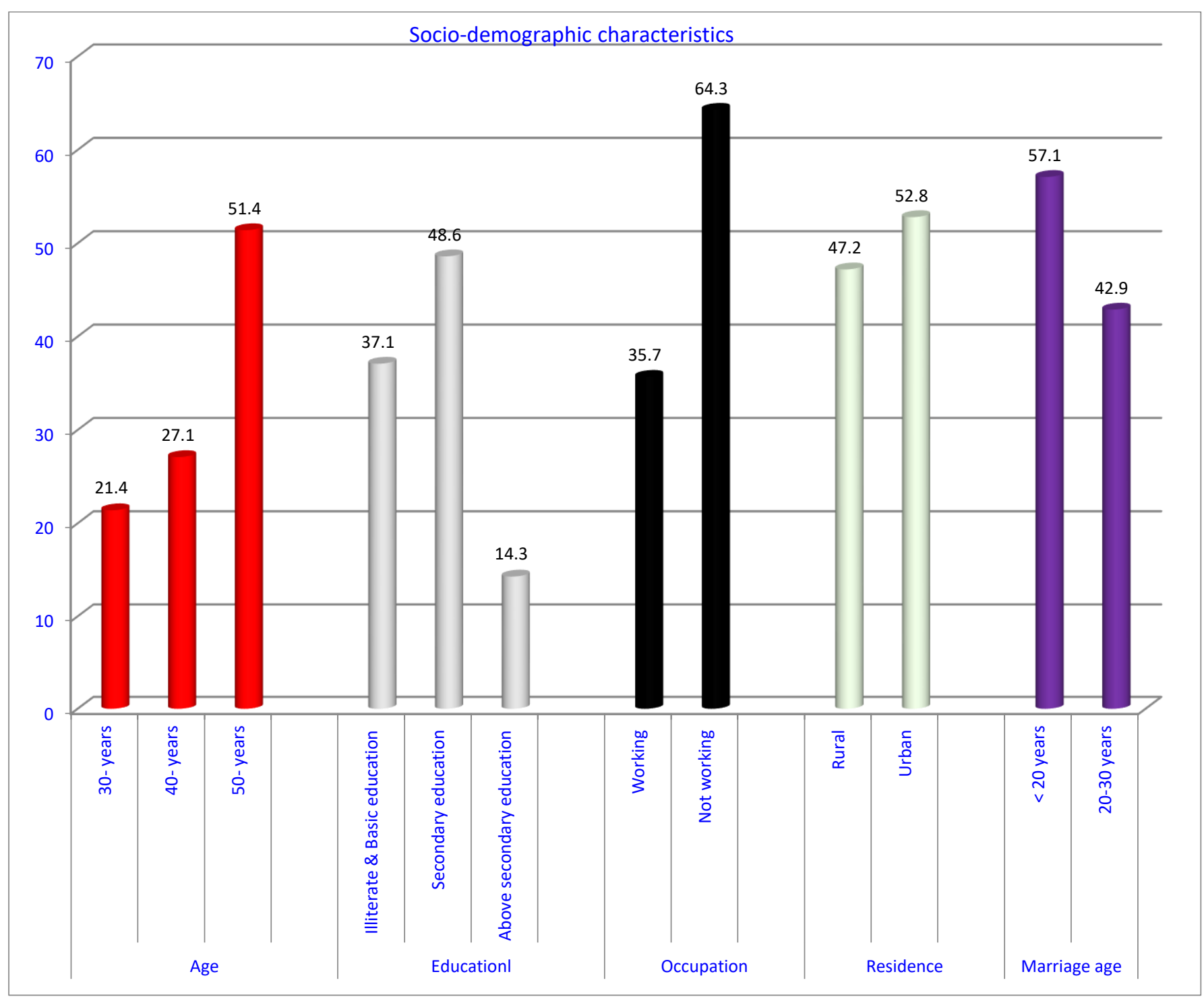

Figure 1: Socio-demographic characteristics of the study subject.

\begin{tabular}{|c|c|c|}
\hline Obstetric and gynecological history & No & $\%$ \\
\hline \multicolumn{3}{|l|}{ 1. Menarche age } \\
\hline$\bullet \quad<12$ years & 13 & 18.6 \\
\hline - $12: 15$ years & 55 & 78.6 \\
\hline$\bullet \quad>15$ years & 2 & 2.8 \\
\hline Mean \pm SD & \multicolumn{2}{|c|}{$12.4 \pm 2.45$} \\
\hline \multicolumn{3}{|l|}{ 2. Menstrual period } \\
\hline • $\quad$ Regular & 18 & 25.7 \\
\hline - $\quad$ Irregular & 23 & 32.9 \\
\hline • Amenorrhea & 29 & 41.4 \\
\hline \multicolumn{3}{|l|}{ 3. $\quad$ Parity number } \\
\hline • $\quad$ No parity & 1 & 1.4 \\
\hline - $\quad$ Two & 6 & 8.6 \\
\hline - $\quad$ Three & 19 & 27.2 \\
\hline - $\quad$ More than three & 44 & 62.8 \\
\hline
\end{tabular}

Table 1: Distribution of the study subjects according to their previous obstetric and gynecological history. 


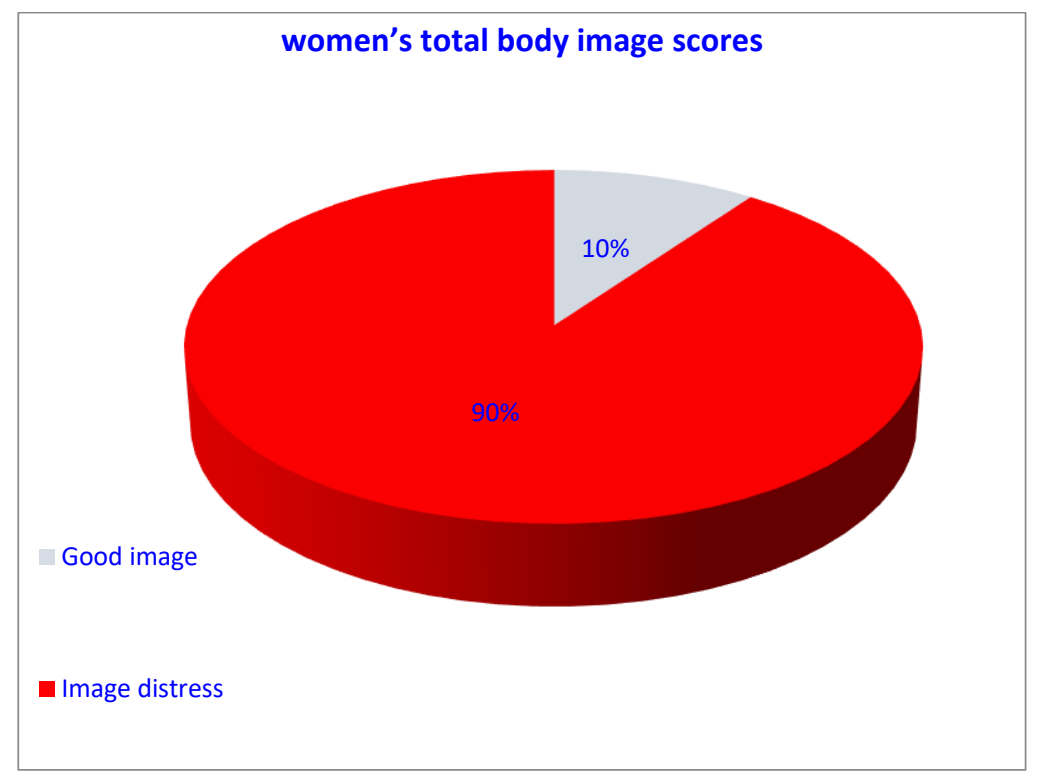

Figure 2: Percentage distribution of women's total body image scores $(n=70)$.

\begin{tabular}{|c|c|c|c|c|c|c|c|}
\hline \multirow{2}{*}{$\begin{array}{c}\text { Demographic } \\
\text { Characteristics }\end{array}$} & \multirow{2}{*}{$\mathbf{N}$} & \multicolumn{2}{|c|}{ Good image } & \multicolumn{2}{|c|}{ Image distress } & \multirow{2}{*}{$\mathbf{X}^{2}$} & \multirow{2}{*}{ P-value } \\
\hline & & No & $\%$ & No & $\%$ & & \\
\hline \multicolumn{8}{|l|}{ 1. Age } \\
\hline - $30:<40$ years & 15 & 4 & 5.7 & 11 & 15.7 & \multirow{3}{*}{5.75} & \multirow{3}{*}{$0.048 *$} \\
\hline - $\quad 40:<50$ years & 19 & 1 & 1.4 & 18 & 25.8 & & \\
\hline$\bullet \quad>50$ years & 36 & 2 & 2.8 & 34 & 48.6 & & \\
\hline \multicolumn{8}{|l|}{ 2. $\quad$ Educational level of women } \\
\hline • $\quad$ Illiterate & 2 & 0 & 0.0 & 0 & 0.0 & \multirow{4}{*}{8.24} & \multirow{4}{*}{0.041} \\
\hline - $\quad$ Basic education & 26 & 5 & 7.2 & 21 & 30.0 & & \\
\hline - $\quad$ Secondary education & 34 & 0 & 0.0 & 34 & 48.6 & & \\
\hline - $\quad$ Above secondary education & 10 & 2 & 2.8 & 8 & 11.4 & & \\
\hline \multicolumn{8}{|l|}{ 3. $\quad$ Residence } \\
\hline$\bullet \quad$ Rural & 33 & 5 & 7.2 & 28 & 40.0 & \multirow{2}{*}{1.63} & \multirow{2}{*}{0.352} \\
\hline - Urban & 37 & 2 & 2.8 & 35 & 50.0 & & \\
\hline \multicolumn{8}{|l|}{ 4. Marriage age } \\
\hline$\bullet \quad<20$ years & 40 & 6 & 5.6 & 34 & 48.6 & \multirow{2}{*}{4.62} & \multirow{2}{*}{$0.038^{*}$} \\
\hline - $20: 30$ years & 30 & 7 & 10.0 & 23 & 32.8 & & \\
\hline
\end{tabular}

(*) statistically significant $p<0.05$

Table 2: relationship between demographic characteristics of the study subjects and their body image scores

\section{Discussion:}

Cervical cancer affects all aspects of a patient's life, including body image and intimacy. Health care providers don't ask patients about it, and women may be uncomfortable broaching the topic on their own. [36-38] In the previous studies, the researchers attempted to conduct one study for evaluating the impact of an educational nursing program of intervention on body image among women with cervical cancer. [39] The results of the current study indicate that the majority $(90 \%)$ of the studied women had body image distress. This is not amazing as Edlund (2019) reported that body image and intimacy after cancer may be different. [19] Other authors reported that cervical cancer affects all aspects of a patient's life, including self-concept, and body image, as well. [1-6]

According to the current study findings, it was revealed that the women with cervical cancer exhibited statistically significant between sociodemographic variables (age, \& age at marriage) and body image. Our findings reinforce the need for gynecologists and professionals as well as health care sectors to look for psychosocial distress in women undergoing cervical cancer treatment. Psychological interventions and improvements in the organization of care are essential to positively impact outcomes during treatment in this group of women.

The current study illustrates that woman's age correlates well with women's self-image; the older women experienced more body image distress. This reflected that the older the woman, the less chance to treatment and their concepts that they will not tolerate surgical, chemical, and radiation interference, so they will be more concerned about their body image. [40] As well, it shows that the same group of women was at risk of developing body image distress. A highly statistically significant difference was observed between women's body image implication and their ages as older women significantly have a worse body image distress. It can conclude that higher distress in older women can be related to their worries about their life. While young ones have social support as they are still young and have more chances and time for treatment. 
As regards age at marriage of the studied subjects, the results of the present study presented that more than half of them (57.1\%) married at age less than 20 years. Furthermore, a significant difference was noticed between women's age at marriage and their body image implication $(\mathrm{p}=0.038)$. This might be ascribable to the fact that day by day life enhances women's experience and improves their knowledge. [41] The current study illustrates that women's, age of marriage correlate well with women's self-image. Women who married younger (less than 20 years old) had more body image distress $(48.6 \%)$ than those who married later at 20-30 years old (32.8\%). A statistically significant difference was observed between women's body image implication and their ages of marriage as younger women significantly have a worse body image distress.

Education for Upper Egyptian women had improved in recent decades. According to the results of the present study, around half $(48.6 \%)$ of the study subjects had a secondary level of education which considers a satisfactory level of education in Egypt. The results of the study illustrated that there was no statistically significant difference in body image status amongst those upper Egyptian women who were undergoing cervical cancer treatment in regards to their educational level. These findings are congruent with the result of Kishanth et.al, (2014), but the results of Beutel's (1999) study were not similar. He denotes that educational level has no significant relation to anxiety and/or depression. [42-43] However, body image distress was less prevalent $(11.4 \%)$ among highly educated women compared to secondary educated women $(48.6 \%)$ and women with basic education (30.0\%). This may be attributed to that; the highly educated women will have better chances to get better work. So, they will be independent and will have more options for treatment. Previous studies found that depression and/or anxiety were observed more in housewives than in outside employees [44-45]. Moreover, Boivin (2003) found that psychological disorders being more common in housewives than in working ones [46].

\section{Conclusions:}

In conclusion, there is a statistical association between body image statuses amongst those women who were undergoing cervical cancer treatment concerning their socio-demographic characteristics.

\section{Recommendations:}

As cervical cancer is associated with high levels of body image distress; our findings reinforce the need for:

1. Gynecologist \& health care professionals to look for this distress in women undergoing cancer treatment.

2. Implement an educational program to improve the self-body image for women with cervical cancer.

\section{References:}

1. Nady F., Said M., Youness E., Hassan H. (2018): Effect of Nursing Intervention Program on Quality of Life Improvement for Women Undergoing Gynecological and Breast Cancer Treatment. Assuit Scientific Nursing Journal,; 6(15): 62-77.

2. Mohammed F., Shahin M., Youness E., Hassan H. (2018). Survivorship in Women Undergoing Gynecological and Breast Cancer Treatment in Upper Egypt: The Impact of Quality of Life Improvement Educational Program". American Research Journal of Gynaecology; 2(1): 1-28. doi:10.21694/2577-5928.18001

3. Hassan H. (2020): Early Stage Cervical Cancer: Survivorship and Fertility preservation. American Research Journal of Oncology; 2(1): 1-3.

4. Carter J., Lacchetti Ch., Andersen B., Barton D., Bolte S., Damast Sh., Diefenbach M., DuHamel K., Florendo J., Ganz P., Goldfarb S., Hallmeyer S., Kushner D., Julia H Rowland J. (2018):
Interventions to Address Sexual Problems in People With Cancer: American Society of Clinical Oncology Clinical Practice Guideline Adaptation of Cancer Care Ontario Guideline. Clin Oncol, 10; 36(5):492-511.

5. Nady F., El-Sherbiny M., Youness E., Hassan H. (2018): Effectiveness of Quality of Life Planned Teaching Program on Women Undergoing Gynecologic Cancer Treatment. American Research Journal of Oncology.

6. Hassan H., Saber N., Sheha E. (2019): Comprehension of Dyspareunia and Related Anxiety among Northern Upper Egyptian women: Impact of Nursing Consultation Context Using PLISSIT Model. Nursing \& Care Open Access Journal.; 6(1): 119.

7. WHO, (2018): Human papillomavirus (HPV) and cervical cancer,

8. Hassan H., Bayoumi M., Atwa A. (2016): Emotional Distress Associated with Gynecologic and Breast Cancer in Beni-Suef City. International Journal of Science and Research; 5(2): 11181129.

9. Zagloul, M., Naser, E., Hassan, H. (2020): Cervical Cancer Knowledge, Attitude, and Practices: Educational Program Management for Female Workers at Port Said University. International Journal of Studies in Nursing, 5(3): 1-16. doi:10.20849/ijsn.v5i3.776.

10. Hassan H. (2020): Early Stage Cervical Cancer: Survivorship and Fertility preservation. American Research Journal of Oncology; 2(1): 1-3.

11. Qalawa, Sh., Eldeeb, A., \& Hassan, H. (2015): Young Adult Women's intention regarding breast and cervical cancer screening in Beni-Suef. Scientific Research Journal, 3(3): 11-24.

12. Said S., Hassan H., Sarhan A. (2018): Effect of an Educational Intervention on Women's Knowledge and Attitude Regarding Cervical Cancer. American Journal of Nursing Research.

13. Mohamed A., Hassan H., Gamel W., Arafa A. (2019): Awareness about breast and cervical cancers among nursing students in BeniSuef University. Journal of Nursing Education and Practice

14. Atwa A., Hassan H., Ahmed S. (2019): The impact of a hospitalbased awareness program on the knowledge of patients about breast cancer and cancer cervix. International Journal of Studies in Nursing

15. Pitcher S., Adams T., van L., Fakie N., Saidu R, Denny L, Moodley J. (2018): Holistic sexuality post gynecological cancer treatment: A review of recent literature. SA journal of oncology;

16. National Cancer Institute. (2014): PDQ treatment summary for health professionals. Cervical cancer.

17. Hassan H., Masaud H., Mohammed R., Ramadan S. (2021): SelfKnowledge and Body Image among Cervical Cancer Survivors' Women in Northern Upper Egypt. Further Applied Healthcare; 1(1): $1-12$

18. Hassan H., Kamal H., Abd El Salam S., Ali R. (2021): Survivors from Cervical Cancer: Impact of an Educational Program on SelfKnowledge and body-Image. Public Health Open Access; 5(2):17. DOI: $10.23880 /$ phoa- 16000175

19. Edlund C. Sexuality, (2019): Intimacy and Cancer: A guide for people with cancer and their partners. Cancer Council Australia. ISBN 9781925651508

20. Abd El Salam., Ali R., Hassan H., Kamal H. (2021): Outcome of an Educational Program on Body Image Distress Associated with Cervical Cancer. Journal of Advanced Trends in Basic and Applied Science; 1(1).

21. Corrêa C., Leite I., Andrade A., Guerra M. (2015): Cervical Cancer Treatment and Its Effects on Sexual Function: Recent Evidence and Approach. Austin J Women's Health; 2(1)

22. Hassan H., Saber N., Sheha E. (2019): Comprehension of Dyspareunia and Related Anxiety among Northern Upper 
Egyptian women: Impact of Nursing Consultation Context Using PLISSIT Model. Nursing \& Care Open Access Journal,; 6(1): 119. DOI: $10.15406 /$ ncoaj.2019.06.00177

23. Salmond, S., \& Echevarria, M., (2017): Healthcare Transformation and Changing Roles for Nursing, PMC journal, $36(1)$.

24. Ramadan E., Eldesokey A., Hassan H. (2020): Effect of an Educational Package on Knowledge, Practices, and Attitude of Premenopausal Women Regarding Sexuality. American Journal of Nursing Research; 8(5): 495-505. doi: 10.12691/ajnr-8-5-2.

25. Hassan H. (2020): Evidence-Based Practice in Midwifery and Maternity Nursing for Excellent Quality of Care Outcomes. American Journal of Nursing Research; 8(6): 606-607.

26. Jasemi, M., Valizadeh, L., Zamanzadeh, V., Keoghm, B., (2017) A Concept Analysis of Holistic Care by Hybrid Model, Indian J Palliat Care.

27. Ali R., Kamal H., Hassan H., Abd El Salam S. (2021): Impact of an Educational Program on Sexual Distress Associated With Cervical Cancer. Further Applied Healthcare; 1(1): 30-42

28. Hassan H., Ali R., Abd El Salam S., Kamal H. (2021): Impact of an Educational Program on Sexual Dysfunction Associated With Cervical Cancer. Journal of Cancer Research and Treatment; 9(2)

29. Hassan H., Atwa A. (2017): Occupational Stress, Job Satisfaction and Cervical Screening Intention of Maternity Oncology Nurses, Medical Science \& Healthcare Practice; 1(1): 48-59. doi:10.22158/mshp.v1n1p48

30. Sun, H., Kyung, H., Man, S., Hee, J. (2018): Online-based interventions for sexual health among individuals with cancer: a systematic review, BMC Health Services Research journal volume; 18, Article number: 167.

31. Ali R., Abd El Salam S., Kamal H., Hassan H. (2021): Women with Cervical Cancer: Impact of an Educational Program their Knowledge. Journal of Obstetrics Gynecology and Reproductive Sciences, 5(2): 1-8. DOI: 10.31579/ 2578-8965/063

32. Hassan H., Mohammed R., Ramadan S., Masaud H. (2021): Impact of an Educational Program on Sexual Issues among Cervical Cancer Survivors' Women in Northern Upper Egypt. Journal of Obstetrics Gynecology and Reproductive Sciences, 5(1): 1-16. DOI: $10.31579 / 2578-8965 / 061$

33. Masaud H., Hassan H., Mohammed R., Ramadan S. (2021): Women's Sexual Distress Associated with Cervical Cancer. Sumerianz Journal of Medical and Healthcare; 4(1): 28-
34. doi.org/10.47752/sjmh.41.28.34

34. Hassan H., Ramadan S., Ali R., Kamal H. (2021): Sexual Issues among Cervical Cancer Survivors' Women in Northern Upper Egypt. Journal of Advanced Trends in Basic and Applied Science; 1(1).

35. Hopwood P., Fletcher I., Lee A., Ghazal S. (2001): A body image scale for use with cancer patients. European Journal of Cancer.

36. Rowland, H., Carter, J. New (2018): ASCO Guideline on Interventions to Address Sexual Problems in People With Cancer; available at;

37. Abd El Salam S., Hassan H., Kamal K., Ali R. (2021): Women's Sexual Dysfunction Associated with Cervical Cancer. Applied Science and Computer Mathematics; 2(1): 17-27.

38. Kamal H., Ali R., Abd El Salam S., Hassan H. (2021): SelfKnowledge among Women with Cervical Cancer. Journal of Cancer Research and Treatment; 9(1)

39. Zhou L., Qing L., Shen B., Jin Z., Liu H., Chen Y. (2017): Patterns and predictors of healthcare-seeking for sexual problems among cervical cancer survivors: An exploratory study in China. Biomed Research journal- India,; 28(14).

40. Sadock B \& Sadock V. (2004): Synopsis of psychiatry, 9th ed. USA: Lippincott Williams and Wilkins

41. Hassan H. (2016): Infertility profile, psychological ramifications and reproductive tract infection among infertile women, in northern Upper Egypt. Journal of Nursing Education and Practice;

42. Beutel M, Kupfer J, Kirchmeyer P, Kehde F, Schroeder-printzen I, et al. (1999): Treatment related stress and depression in couples undergoing assisted reproductive treatment by IVF or ICSI. Andrologia, 31 (1): 27-35.

43. Kishanth O, Prema K \& Susila C. (2014): Level of anxiety among women with infertility problems, at Pondicherry city hospital, Puducherry; A Descriptive study. International Journal of Comprehensive Nursing, 2014; 1 (1).

44. Upkong D. \& Orji E (2006) Mental health of infertile women in Nigeria. Winter; 17 (4): 259-65.

45. Ramezanzadeh F, Aghssa M, Abedinia N, Zayeri F, Khanafshar N, Shariat M, \& Jafarabadi M. (2004): A Survey of Relationship between Anxiety, Depression and Duration of Infertility. BMC women's health; 4:9.

46. Boivin J. (2003): A review of psychological interventions in infertility. Soc sci med; 57:2325-2341. 